\title{
Centella asiatica (L.) Urban Leaf Extracts Inhibit the Growth of Bacterial Triggers of Selected Autoimmune Inflammatory Diseases and Potentiate the Activity of Conventional Antibiotics
}

\author{
Yan Zhang ${ }^{1}$, Zihao Yang ${ }^{1}$, lan Edwin Cock ${ }^{1,2 *}$ \\ 'School of Natural Sciences, Nathan Campus, Griffith University, Brisbane, AUSTRALIA. \\ 2Environmental Futures Research Institute, Nathan Campus, Griffith University, Brisbane, Queensland, AUSTRALIA.
}

\begin{abstract}
Introduction: An increase in antibiotic resistance and a corresponding decrease in antimicrobial discovery have directed researchers towards alternative therapies, including plant based medicines. However, synergistic combinations of plant extracts with conventional antibiotics may be a far more effective approach in overcoming resistance and potentiating the activity of antibiotics that are otherwise ineffective against resistant bacterial strains. Methods: The antibacterial activity of Centella asiatica (Gotu Kola) extracts was investigated by disc diffusion and quantified by liquid dilution and solid phase $\mathrm{MIC}$ assays. The extracts were also combined with a range of conventional antibiotics and tested against various microbial triggers of autoimmune diseases. The $\Sigma$ FIC values obtained from these assays were used to determine the class of combinational effects and isobologram analysis was used to determine the ideal synergistic ratio(s). Toxicity was evaluated by Artemia nauplii mortality assays. Results: The methanolic extracts showed good inhibitory activity against several microbial triggers of autoimmune inflammatory diseases, whilst the chloroform and hexane extracts were also potent inhibitors of $K$. pneumoniae growth. Combinations of the C. asiatica extracts with conventional antibiotics were often substantially more effective in inhibiting bacterial growth. One synergistic and 10 additive interactions were noted. Notably, the methanolic extract restored significant growth inhibitory activity to chloramphenicol and tetracycline when tested in combination against $K$. pneumoniae. In contrast, two antagonistic
\end{abstract}

interactions were noted for combinations containing gentamycin (against A. baylyi and $S$. pyogenes), indicating that those combinations should be avoided when treating infections caused by those bacteria. Conclusion: C. asiatica extracts have potential as inhibitors of bacterial triggers of selected autoimmune inflammatory diseases. Furthermore, extract components may also potentiate the activity of two antibiotics that are relatively ineffective alone. Isolation of these agents may be beneficial in drug design against several bacteria, including the microbial triggers of rheumatoid arthritis, ankylosing spondylitis and multiple sclerosis

Key words: Synergy, Conventional antimicrobials, Interaction, Medicinal plants, Rheumatoid arthritis, Ankylosing spondylitis, Multiple sclerosis, Drug combinations

\section{Correspondence:}

Dr. Ian Edwin Cock

'School of Natural Sciences, Nathan Campus, Griffith University, Brisbane, AUSTRALIA.

'Environmental Futures Research Institute, Nathan Campus, Griffith University, Brisbane, Queensland-4111, AUSTRALIA.

Phone no: +61 737357637

E-mail: i.cock@griffith.edu.au

DOI: $10.5530 /$ pc.2020.3.24

\section{INTRODUCTION}

Despite their initial efficacy, the overuse of antibiotics has resulted in a wide range of bacterial pathogens developing resistance towards multiple antibiotics. ${ }^{1}$ Additionally, the discovery of new antimicrobial agents has decreased dramatically in recent years, making many bacterial infections difficult to manage using current therapeutic strategies. ${ }^{2}$ The development of alternative antibacterial treatment modalities is considered by the World Health Organisation (WHO) to be perhaps the biggest challenge currently facing medical science. ${ }^{3}$ For a number of reasons reviewed elsewhere, ${ }^{2}$ it is unlikely that the current methods of antibiotic discovery/development will be as successful in the future. This is particularly true for the treatment of autoimmune inflammatory diseases. These are a group of debilitating diseases including rheumatoid arthritis (RA), ankylosing spondylitis (AS), lupus, Lyme disease, multiple sclerosis (MS), celiac disease and rheumatic fever (RV). ${ }^{4}$ All of these diseases result from an abnormal immune response to self-tissue as a consequence of antigen challenge, often by bacterial pathogens. There is currently no cure for any of these diseases and the current treatment strategy is to alleviate the symptoms with analgesics and anti-inflammatory therapies. However, as RA, AS, MS and RV are induced in genetically people by bacterial pathogens, a more effective preventative treatment may be to target the growth of the specific trigger bacteria, thereby blocking the disease etiological events. ${ }^{4}$ Whilst antibiotics are already available for the treatment of all of these bacteria, the development of resistant strains in recent years have decreased their efficacy. ${ }^{1}$ Furthermore, the prophylactic use of pure antibiotics over prolonged periods would certainly induce resistance, thereby rendering the bacteria refractory to their actions. A better approach may be to use combinations of antibacterial components. ${ }^{2}$

Traditional medicines have great potential for antimicrobial drug development. Despite this, relatively few plant derived antibiotic compounds are in common use clinically. This may be because synergistic interactions are often required to potentiate the antibacterial activity and purified compounds often have much lower activity than the crude extract. ${ }^{5} \mathrm{~A}$ combinational approach that allows synergistic interaction between plant extracts (or pure plant compounds) and conventional antibiotics may be more effective in combatting bacterial pathogens, especially antibiotic resistant strains. ${ }^{6,7}$ Combinational therapies are already preferred over mono-therapy to treat multiple lifethreatening infectious diseases such as malaria, tuberculosis and HIV/ AIDS due to their ability to target multiple facets of a disease and to curb resistance. ${ }^{2}$ Combinations of plant extracts/isolated compounds with conventional antibiotics may also prove to have economic advantages. ${ }^{5}$ Developing a new drug requires years of extensive and costly testing. However, combinational therapy can potentially restore an existing drug to a state of significantly reduced resistance, thereby bypassing the lengthy and expensive process of discovering new antimicrobial agents. ${ }^{5}$ Furthermore, synergistic combinations may have increased efficiency, reduced side effects, increased stability and bioavailability and 
require lower doses in comparison to synthetic alternatives to achieve therapeutic outcomes. ${ }^{6}$

Centella asiatica (L.) Urban (commonly known as Gotu Kola and Indian pennywort; Family Apiaceae) is a medicinal plant that is native to wetland regions of Asia. It is particularly prevalent in India, Madagascar and Sri Lanka, but also occurs in southern Africa, Australia, China, Indonesia and throughout the South Pacific region. In India, C. asiatica is used to treat skin conditions associated with eczema, lupus and psoriasis and for varicose ulcers. ${ }^{8}$ It is also particularly beneficial in female conditions such as amenorrhea and diseases of the urogenital tract. It is also used in traditional Chinese medicine (TCM) for treating fevers, dysentery and urinary tract infections, as well as infectious hepatitis and jaundice. ${ }^{9} \mathrm{C}$. asiatica decoctions have also been reported to be effective as an antidote for poisoning by arsenic, toxic mushrooms and Gelsemium elegans (Gardner and Chapm.) Benth.,. A poultice is also applied externally to treat snakebites, scabies, herpes, fractures, contusions and sprains. ${ }^{9}$ However, despite its well documented traditional uses, there has been relatively little research into the therapeutic properties of $C$. asiatica.

Several studies have reported growth inhibitory effects of C. asiatica essential oils against a panel of bacterial pathogens including Bacillus subtilus, Staphylococcus aureus, Escherichia coli and Shigella sonnei. ${ }^{10}$ The oil is a particularly good inhibitor of gram negative bacteria, with MIC values as low as $39 \mu \mathrm{g} / \mathrm{mL}$ recorded against $E$. coli. It also inhibited the growth of gram positive bacteria, although the MIC values obtained indicated more moderate growth inhibition. Similarly, leaf extracts are good inhibitors of a panel of bacteria, including several of the same species. ${ }^{11}$ However, that study tested a single high concentration of each extract using an agar diffusion technique. MIC values were not determined, making comparisons with other studies impossible. Chemical profiling of $C$. asiatica essential oil has identified high levels of the sesquiterpenoid germacrene. This compound has strong antimicrobial activity and is likely to contribute to the antibacterial effects of $C$. asiatica. Despite these earlier studies, $C$. asiatica preparations are yet to be tested against the bacterial triggers of rheumatoid arthritis (Proteus mirabilis), ankylosing spondylitis (Klebsiella pneumoniae), multiple sclerosis (Acinetobacter baylyi, Pseudomonas aeruginosa) and rheumatic fever (Streptococcus pyogenes). ${ }^{4}$ Furthermore, we were unable to find any studies testing the antibacterial activity of $C$. asiatica extracts in combination with conventional antibiotics. Therefore, this study was undertaken to investigate the antimicrobial effects of $C$. asiatica extracts and their ability to potentiate the growth inhibitory properties of conventional antibiotics against the bacterial triggers of some autoimmune inflammatory diseases.

\section{MATERIALS AND METHODS}

\section{Plant source and extraction}

Certified C. asiatica (L.) Urban leaf powder was obtained from Noodles Herbal Emporium, Australia and a voucher specimen (GU2017aGC) was deposited in the School of Natural Sciences, Griffith University, Australia. Individual $1 \mathrm{~g}$ masses of the ground plant material were weighed into separate $50 \mathrm{~mL}$ Falcon tubes and $50 \mathrm{~mL}$ of methanol, deionised water, ethyl acetate, chloroform or hexane were individually added. All solvents were obtained from Ajax Fine Chemicals, Australia and were AR grade. The ground plant materials were extracted in each solvent for $24 \mathrm{~h}$ at $4^{\circ} \mathrm{C}$ with gentle shaking. The extracts were filtered through Whatman No. 54 filter paper under vacuum and the solvent extracts were air dried at room temperature in the shade. The aqueous extracts were lyophilised by freeze drying at $-50^{\circ} \mathrm{C}$. The resultant dried extracts were weighed to determine the extraction yield and then dissolved in $10 \mathrm{~mL}$ deionised water (containing 1\% DMSO).

\section{Qualitative phytochemical studies}

Phytochemical analysis of the C. asiatica extracts for the presence of alkaloids, cardiac glycosides, flavonoids, phenolic compounds, phytosterols, saponins, tannins and triterpenoids was achieved as previously described. ${ }^{12,13}$

\section{Antibacterial screening}

\section{Conventional Antibiotics}

Penicillin-G (1440-1680 $\mu \mathrm{g} / \mathrm{mg})$, chloramphenicol ( $\geq 98 \%$ purity), erythromycin $(\geq 850 \mu \mathrm{g} / \mathrm{mg})$, gentamycin $(600 \mu \mathrm{g} / \mathrm{mg})$ and tetracycline ( $\geq 95 \%$ purity) were purchased from Sigma-Aldrich, Australia and used for the microplate liquid dilution assay. All antibiotics were prepared in sterile deionised water at stock concentrations of $0.01 \mathrm{mg} / \mathrm{mL}$ and stored at $4^{\circ} \mathrm{C}$ until use. For the disc diffusion studies, ampicillin $(10 \mu \mathrm{g})$ and chloramphenicol $(10 \mu \mathrm{g})$ standard discs were obtained from Oxoid Ltd., Australia and used as positive controls.

\section{Bacterial cultures}

All bacterial strains were selected based on their ability to trigger autoimmune inflammatory diseases in genetically susceptible individuals. ${ }^{4}$ Reference strains of Proteus mirabilis (ATCC21721), Proteus vulgaris (ATCC21719), Klebsiella pneumoniae (ATCC31488), Acinetobacter baylyi (ATCC33304) and Pseudomonas aeruginosa (ATCC39324) were purchased from American Type Culture Collection, USA. A clinical isolate strain of Streptococcus pyogenes was obtained from the School of Environment and Science teaching laboratory, Griffith University, Australia. All bacteria were cultured in nutrient broth (Oxoid Ltd., Australia). Streak nutrient agar (Oxoid Ltd., Australia) plates were tested in parallel to ensure the purity of all bacterial cultures and for subculturing. All bacterial cultures were incubated at $37^{\circ} \mathrm{C}$ for $24 \mathrm{~h}$ and were subcultured and maintained in nutrient broth at $4^{\circ} \mathrm{C}$ until use.

\section{Evaluation of antibacterial activity}

Antibacterial activity screening of the C. asiatica extracts was assessed using a modified disc diffusion assay. ${ }^{12,13}$ Ampicillin (10 $\left.\mu \mathrm{g}\right)$ and chloramphenicol discs $(10 \mu \mathrm{g})$ were obtained from Oxoid Ltd., Australia and used as positive controls to compare antibacterial activity. Filter discs infused with $10 \mu \mathrm{L}$ of distilled water (containing 1\% DMSO) were used as a negative control.

\section{Minimum inhibitory concentration (MIC) determination}

The minimum inhibitory concentration for each extract was determined using two methods. A liquid dilution MIC assay was employed as it is generally considered the most sensitive bacterial growth inhibitory assay. ${ }^{14}$ Furthermore, as microplate liquid dilution MIC assays are perhaps the most commonly used method of quantifying bacterial growth inhibition efficacy, use of this method facilitates comparisons with other studies. A solid phase agar disc diffusion assay was also used in this study for comparison as it more accurately represents the growth patterns of the bacteria on solid surfaces.

\section{Microplate liquid dilution MIC assay}

The MICs of the extracts were evaluated by standard methods. ${ }^{15}$ All plates were incubated at $37^{\circ} \mathrm{C}$ for $24 \mathrm{~h}$. p-Iodonitrotetrazolium violet (INT) was obtained from Sigma-Aldrich, Australia and dissolved in sterile deionised water to prepare a $0.2 \mathrm{mg} / \mathrm{mL}$ INT solution. A $40 \mu \mathrm{L}$ volume of this solution was added into all wells and the plates were incubated for a further $6 \mathrm{~h}$ at $37^{\circ} \mathrm{C}$. Following incubation, the MIC was visually determined as the lowest dose at which colour development was inhibited. 


\section{Disc diffusion MIC assay}

The minimum inhibitory concentrations (MIC) of the extracts was also evaluated by disc diffusion assay as previously described. ${ }^{12,13}$ Graphs of the zone of inhibition versus ln concentration were plotted and MIC values were achieved using linear regression.

\section{Sum of fractional inhibitory concentration ( $\Sigma \mathrm{FIC})$ assessment}

Interactions between the $C$. asiatica extracts and the conventional antibiotics were examined by determination of the sum of fractional inhibitory concentrations ( $\mathrm{FIC}$ ) for each combination. ${ }^{15}$ The FIC values for each component ( $\mathrm{a}$ and $\mathrm{b}$ ) were calculated using the following equations where a represents the plant extract sample and $b$ represents the conventional antibiotic:

$$
\begin{aligned}
& \text { FIC }(\mathrm{a})=\left(\frac{\text { MIC }[\mathrm{a} \text { in combination with } \mathrm{b}]}{\text { MIC }[\mathrm{a} \text { independently }]}\right) \\
& \text { FIC }(\mathrm{b})=\left(\frac{\text { MIC }[\mathrm{b} \text { in combination with } \mathrm{a}]}{\text { MIC }[\mathrm{b} \text { independently }]}\right)
\end{aligned}
$$

The $\Sigma$ FIC was then calculated using the formula $\Sigma$ FIC $=$ FIC(a) + FIC(b). The interactions were classified as synergistic $(\Sigma$ FIC $\leq 0.5)$, additive $(\Sigma$ FIC $>0.5-1.0)$, indifferent $(\Sigma$ FIC $>1.0-4.0)$ or antagonistic $(\Sigma$ FIC $>4.0) .{ }^{15}$

Varied ratio combination studies (isobolograms)

For each combination producing synergistic interactions, nine different ratios spanning the range 10:90 (extract:antibiotic) to 90:10 (extract:antibiotic) were tested. All combinations were tested in duplicate in two independent experiments, providing four replicates for each combination ratio. The data is presented as the mean of four replicates. Data points for each ratio examined were plotted on a isobologram and this was used to determine optimal combination ratios to obtain synergy. Data points on or below the 0.5:0.5 line indicate synergy; those above the 0.5:0.5 line, up to and including the 1.0:1.0 line indicate an additive interaction; data points above the 1.0:1.0 line indicate indifferent interaction.

\section{Toxicity screening}

Two assays were used to assess the toxicity of the individual samples. The Artemia nauplii lethality assay (ALA) was utilised for rapid preliminary toxicity screening, whereas the MTT cellular proliferation assay was used to determine a cellular evaluation of toxicity.

\section{Artemia franciscana Kellogg nauplii toxicity screening}

Potassium dichromate $\left(\mathrm{K}_{2} \mathrm{Cr}_{2} \mathrm{O}_{7}\right)$ (AR grade, Chem-Supply, Australia) was prepared in deionised water $(4 \mathrm{mg} / \mathrm{mL})$ and serially diluted in artificial seawater as a reference toxin. Toxicity of the C. asiatica extracts, reference toxin and conventional antibiotics was assessed using a modified Artemia franciscana nauplii lethality assay. ${ }^{16,17}$ The $\mathrm{LC}_{50}$ with 95\% confidence limits for each treatment was calculated using probit analysis.

\section{Cellular viability assay}

All extracts were also screened individually using a normal human primary dermal fibroblast (HDF) standard assay. ${ }^{18}$ Briefly, the HDF cells were obtained from American Type Culture Collection (ATCC PCS-201-012) and were cultured and maintained in Dulbecco's modified eagle medium (DMEM; ThermoFisher Scientific, Australia), supplemented with $10 \%$ foetal calf serum (Life Technologies, Australia), $50 \mu \mathrm{g} / \mathrm{mL}$ streptomycin (Sigma-Aldrich, Australia) and $50 \mathrm{IU} / \mathrm{mL}$ penicillin (Sigm-Aldricha, Australia) at $37^{\circ} \mathrm{C}, 5 \% \mathrm{CO}_{2}$ in a humidified atmosphere. Individual $70 \mu \mathrm{L}$ volumes of culture media (containing approximately 5000 cells) were added to wells of a 96 well plate and $30 \mu \mathrm{L}$ of the test extracts or cell media (for the negative control) was added to each well. The plates were incubated at $37^{\circ} \mathrm{C}, 5 \% \mathrm{CO}_{2}$ for $24 \mathrm{~h}$ in a humidified atmosphere. All extracts were screened at $200 \mu \mathrm{g} / \mathrm{mL}$. The cells were then washed in PBS ( $\mathrm{pH}$ 7.2) to remove interference due to sample colour. A $20 \mu \mathrm{L}$ volume of Cell Titre 96 Aqueous One solution (Promega) was added to each well and the plates were incubated for a further $3 \mathrm{~h}$. Absorbances were recorded at a test wavelength of $540 \mathrm{~nm}$ and a blank wavelength of $690 \mathrm{~nm}$ using a Molecular Devices, Spectra Max M3 plate reader. All tests were performed in at least triplicate and triplicate controls were included on each plate. The $\%$ cellular viability of each test was calculated using the following formula:

$\%$ cellular viability $=\frac{\text { Abs test sample }-(\text { mean Abs control }- \text { mean Abs blank })}{(\text { mean Abs control }- \text { mean Abs blank })}$

Cellular viability $\leq 50 \%$ of the untreated control indicated toxicity, whereas extracts or controls with $>50 \%$ untreated control viability were deemed to be nontoxic.

Statistical analysis

Data is expressed as the mean \pm SEM of at least three independent experiments. One way ANOVA was used to calculate statistical significance between the negative control and treated groups with a $P$ value $<0.01$ considered to be statistically significant.

\section{RESULTS}

Liquid extraction yields ranged from $124 \mathrm{mg}$ (C. asiatica hexane extract) to $238 \mathrm{mg}$ (methanolic C. asiatica extract) (Table 1). Qualitative phytochemical screening (Table 1) showed that the higher polarity solvents (methanol and water) extracted the greatest mass and widest diversity of phytochemical classes

\section{Bacterial growth inhibition screening Inhibition of bacterial triggers of rheumatoid arthritis (P. mirabilis and P. vulgaris)}

P. mirabilis growth was inhibited by the mid to high polarity $C$. asiatica water, methanol and ethyl acetate extracts (Figure 1). The methanolic extract was the strongest inhibitor of $P$. mirabilis growth (as judged by ZOI), with a ZOI of $18.2 \pm 0.4 \mathrm{~mm}$. A volume of $10 \mu \mathrm{L}$ of this extract was infused into the disc, which equates to approximately $240 \mu \mathrm{g}$ of extract infused into the disc. The ZOI for this extract is substantially larger than that of the chloramphenicol controls $(12.5 \pm 0.5 \mathrm{~mm})$. Notably, the chloramphenicol control antibiotic was pure and was tested and at relatively high dose $(10 \mu \mathrm{g} / \mathrm{disc})$. In contrast, the extracts were crude mixtures and the antimicrobial compounds would be expected to account for a small \% of the total extract mass. Therefore, the methanolic extract was considered to be a particularly effective inhibitor of $P$. mirabilis growth and may be effective in the prevention and treatment of rheumatoid arthritis. Interestingly, this bacterium was resistant to the ampicillin control. The aqueous and ethyl acetate extracts had substantially smaller ZOIs than the methanolic extract, $(9.2$ and $7.2 \mathrm{~mm}$ respectively), although this inhibition was still noteworthy. In contrast, the chloroform and hexane extracts were completely ineffective against P. mirabilis growth. Similar inhibitory trends were noted for P. vulgaris growth (Figure 2), although slightly smaller ZOIs were measured. As for $P$. mirabilis, the methanolic extract was the strongest inhibitor of $P$. vulgaris growth (ZOI $14.8 \pm 0.4 \mathrm{~mm}$ ). The ZOIs measured for the methanolic extract were similar to those recorded for the pure chloramphenicol control and substantially bigger than those noted for the ampicillin control $(7.6 \mathrm{~mm})$. Whilst also displaying inhibitory activity, the aqueous and ethyl acetate extracts had substantially lower efficacy than the methanolic extract, with ZOIs of 8.5 and $6.6 \mathrm{~mm}$ respectively. All other extracts were ineffective at inhibiting $P$. vulgaris growth. 


\section{Inhibition of a bacterial trigger of ankylosing spondylitis} (K. pneumoniae)

Most of the C. asiatica extracts inhibited the growth of K. pneumonia, albeit with much smaller ZOIs than measured for the Proteus spp. (Figure 3). The methanolic and chloroform extracts were the strongest growth inhibitors (ZOIs of 8.3 and $8.6 \mathrm{~mm}$ respectively). These ZOIs were comparable to that of the ampicillin control $(8.4 \mathrm{~mm})$, but substantially smaller than those measured for chloramphenicol $(12.6 \mathrm{~mm})$. Only the ethyl acetate extract was completely ineffective against $K$. pneumonia, although it is noteworthy that this extract was tested at a substantially lower concentration $(\sim 5 \mathrm{mg} / \mathrm{mL})$ than the other $C$. asiatica extracts, which may account for its lack of apparent inhibitory activity against this bacterium. As K. pneumoniae can induce ankylosing spondylitis in genetically susceptible individuals, ${ }^{4}$ the $C$. asiatica extracts (particularly the methanolic and chloroform extracts) may be beneficial in the prevention and treatment of that disease.

\section{Inhibition of bacterial triggers of multiple sclerosis ( $A$. baylyi and P. aeruginosa)}

The methanolic, $R$. canina extract also inhibited $A$. baylyi growth, with a ZOI of $9.3 \pm 0.6 \mathrm{~mm}$ (Figure 4 ). This A. baylyi strain was highly susceptible to ampicillin and chloramphenicol, ZOIs of 11.6 and $14.3 \mathrm{~mm}$ respectively. The aqueous and ethyl acetate extracts also inhibited $A$. baylyi growth, although the small ZOIs ( 7.3 and $6.8 \mathrm{~mm}$ respectively) that indicate only low inhibitory activity. In contrast, the P. aeruginosa strain tested in this study was completely resistant to all of the C. asiatica extracts (Figure 5). However, it is noteworthy that this was a particularly resistant bacterium. It was also completely resistant to the ampicillin control and displayed only low sensitivity towards chloramphenicol, with a ZOI of $\sim 7.3 \mathrm{~mm}$. Despite the lack of activity against P. aeruginosa, the

Table 1: The mass of dried extracted material, the concentration after resuspension in deionised water and qualitative phytochemical screenings of the $C$. asiatica extracts.

\begin{tabular}{|c|c|c|c|c|c|c|c|c|c|c|c|c|c|c|c|}
\hline 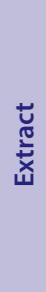 & 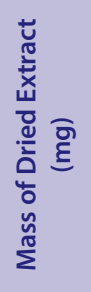 & 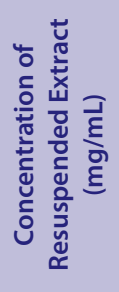 & $\begin{array}{l}\frac{\tilde{U}}{0} \\
\frac{0}{0} \\
\frac{\tilde{c}}{0} \\
\frac{\pi}{0} \\
\stackrel{0}{\circ}\end{array}$ & 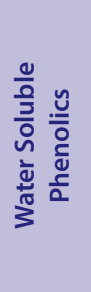 & 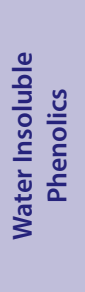 & 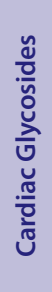 & \begin{tabular}{l}
$\stackrel{n}{\frac{n}{c}}$ \\
\hdashline 0 \\
$\stackrel{0}{0}$ \\
$\stackrel{0}{n}$
\end{tabular} & 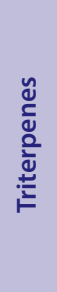 & 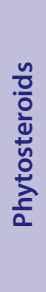 & 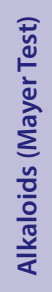 & 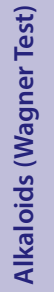 & $\begin{array}{l}\frac{n}{0} \\
\frac{0}{0} \\
\frac{0}{0} \\
\frac{\pi}{4}\end{array}$ & 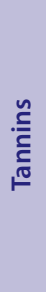 & 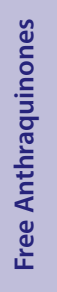 & 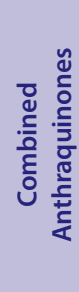 \\
\hline$M$ & 238 & 23.8 & +++ & ++ & +++ & - & - & - & - & - & - & +++ & + & - & - \\
\hline W & 260 & 26.0 & +++ & +++ & ++ & - & + & + & - & - & - & +++ & + & - & - \\
\hline$E$ & 49 & 4.9 & + & + & - & - & - & - & - & - & - & + & - & - & - \\
\hline C & 199 & 19.9 & - & - & + & - & - & - & - & - & - & - & - & - & - \\
\hline $\mathrm{H}$ & 124 & 12.4 & - & - & + & - & - & - & - & - & - & - & - & - & - \\
\hline
\end{tabular}

+++ indicates a large response; ++ indicates a moderate response; + indicates a minor response; - indicates no response in the assay. $\mathrm{W}=$ aqueous extract; $\mathrm{M}=$ methanolic extract; $\mathrm{C}=$ chloroform extract; $\mathrm{H}=$ hexane extract; $\mathrm{E}=$ ethyl acetate extract.

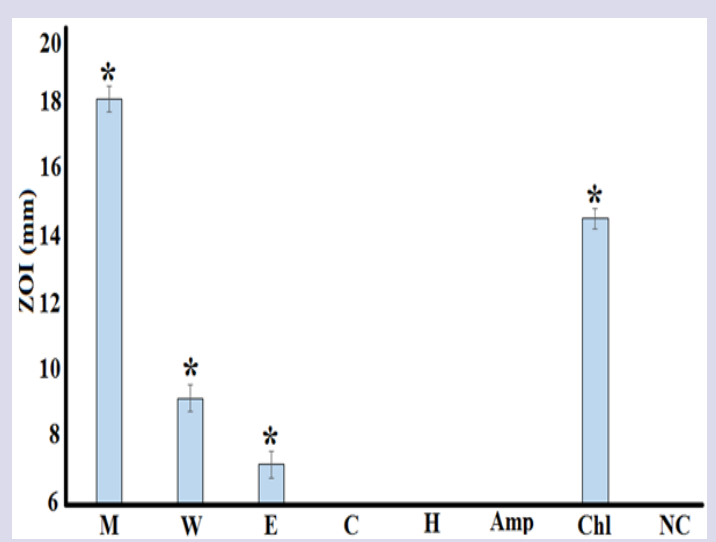

Figure 1: Antibacterial activity of C. asiatica extracts against $P$. mirabilis (ATCC21721) measured as zones of inhibition ( $\mathrm{mm}$ ). $\mathrm{M}=$ methanolic extract; $\mathrm{W}=$ aqueous extract; $\mathrm{E}=$ ethyl acetate extract; $\mathrm{C}=$ chloroform extract; $\mathrm{H}=$ hexane extract. The positive controls were Amp (ampicillin $10 \mu \mathrm{g})$ and $\mathrm{Chl}$ (chloramphenicol $10 \mu \mathrm{g}$ ). Negative control (NC) = water (1\% DMSO). Results are expressed as mean zones of inhibition of two independent repeats, each with internal triplicates $(n=6) \pm$ SEM. * indicates results that are significantly different to the negative control $(P<0.01)$.

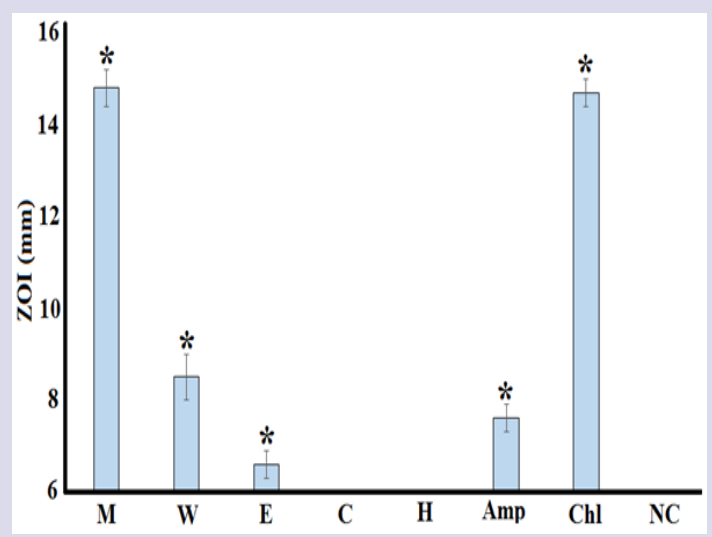

Figure 2: Antibacterial activity of $C$. asiatica extracts against $P$. vulgaris (ATCC21719) measured as zones of inhibition $(\mathrm{mm}) . \mathrm{M}=$ methanolic extract; $\mathrm{W}=$ aqueous extract; $\mathrm{E}=$ ethyl acetate extract; $\mathrm{C}=$ chloroform extract; $\mathrm{H}=$ hexane extract. The positive controls were Amp (ampicillin $10 \mu \mathrm{g}$ ) and $\mathrm{Chl}$ (chloramphenicol $10 \mu \mathrm{g}$ ). Negative control (NC) = water (1\% DMSO). Results are expressed as mean zones of inhibition of two independent repeats, each with internal triplicates $(n=6) \pm$ SEM. * indicates results that are significantly different to the negative control $(P<0.01)$. 
C. asiatica extracts may still be useful in preventing the onset of multiple sclerosis as $A$. baylyi and P. aeruginosa can induce multiple sclerosis in genetically susceptible people. ${ }^{4}$

\section{Inhibition of a bacterial trigger of rheumatic fever (S. pyogenes)}

S. pyogenes growth was inhibited by the methanolic, aqueous and ethyl acetate C. asiatica extracts (Figure 6). The chloroform and hexane extracts were completely ineffective at inhibiting the growth of this bacterium. The methanolic extract was the strongest growth inhibitor, albeit with relatively small ZOIs (ZOI $\sim 7.8 \mathrm{~mm}$ ). Notably, this inhibition was comparable to that of chloramphenicol (ZOI $\sim 8.2 \mathrm{~mm}$ ). This is noteworthy as the chloramphenicol control was pure and was tested at relatively high doses $(10 \mu \mathrm{g} / \mathrm{disc})$. In contrast, $S$. pyogenes was substantially more susceptible to ampicillin $(\sim 12.4 \mathrm{~mm})$ The water and ethyl acetate extracts also inhibited $S$. pyogenes growth, albeit with substantially smaller ZOIs (7.3 and $6.6 \mathrm{~mm}$ respectively), indicating low to moderate growth inhibitory activity. As $S$. pyogenes can trigger rheumatic fever in genetically susceptible people,${ }^{4}$ the C. asiatica methanolic extract (and to a lesser extent, the aqueous and ethyl acetate extracts) may be effective in the prevention and treatment of this disease (and other diseases caused by this bacterium).

\section{Quantification of minimum inhibitory concentration (MIC)}

The relative antimicrobial strength of the extracts was further evaluated by determining the MIC values using two methods: the liquid dilution MIC assay and the disc diffusion MIC assay (Table 2). Consistent with the antibacterial screening assays, the higher polarity methanol and water $C$. asiatica extracts were generally most effective at inhibiting the growth of the bacterial triggers of the selected autoimmune diseases. The complete lack of inhibition of $P$. aeruginosa by all $C$. asiatica extracts was the exception to this trend. The MIC values of the conventional antibiotic controls were only determined for the liquid dilution assay. Commercially manufactured discs with set amounts of antibiotics loaded were used for the disc diffusion assay and thus the zones of

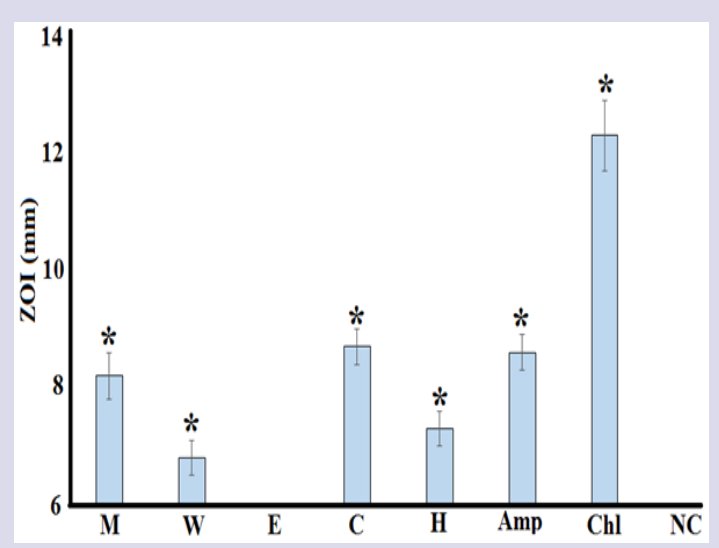

Figure 3: Antibacterial activity of C. asiatica extracts against extracts against K. pneumoniae (ATCC31488) measured as zones of inhibition $(\mathrm{mm}) . \mathrm{M}=$ methanolic extract; $\mathrm{W}=$ aqueous extract; $\mathrm{E}=$ ethyl acetate extract; $\mathrm{C}=$ chloroform extract; $\mathrm{H}=$ hexane extract. The positive controls

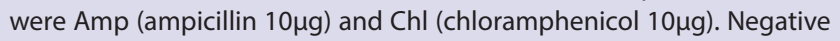
control (NC) = water (1\% DMSO). Results are expressed as mean zones of inhibition of two independent repeats, each with internal triplicates $(n=6) \pm$ SEM. * indicates results that are significantly different to the negative control $(P<0.01)$. only single doses were recorded. Gentamycin was generally the most potent antibiotic (as judged by its MIC) and was the only antibiotic to inhibit the growth of all of the bacterial species tested. Notably, the $P$. aeruginosa strain used in these studies was resistant to all of antibiotics except gentamycin. Furthermore, with the exception of $P$. mirabilis and P. vulgaris, all of the other bacterial strains were completely resistant to penicillin.

The MIC values determined for the C. asiatica extracts compare relatively well between the disc diffusion and liquid dilution assays with some notable exceptions. All bacterial species except $P$. aeruginosa were most susceptible to the methanolic extract, although the ethyl acetate extract had similar efficacy towards the Proteus spp. and S. pyogenes (based on MIC values). The growth of $P$. mirabilis was inhibited by methanolic (DD MIC $800 \mu \mathrm{g} / \mathrm{mL}$; LD MIC $672 \mu \mathrm{g} / \mathrm{mL}$ ) and ethyl acetate extracts (DD MIC $1200 \mu \mathrm{g} / \mathrm{mL}$; LD MIC $850 \mu \mathrm{g} / \mathrm{mL}$ ) with MIC values that indicate noteworthy growth inhibitory activity. The aqueous extract was also a moderate inhibitor of this bacterium (DD MIC 1742 $\mu \mathrm{g}$ / $\mathrm{mL}$; LD MIC $1570 \mu \mathrm{g} / \mathrm{mL}$ ). Similar, albeit slightly higher MIC values were also determined for these extracts against $P$. vulgaris. Therefore, these extracts may be useful in the prevention and treatment of rheumatoid arthritis. The methanolic extract was also a strong inhibitor of K. pneumoniae growth (DD MIC $950 \mu \mathrm{g} / \mathrm{mL}$; LD MIC $672 \mu \mathrm{g} / \mathrm{mL}$ ). Notably, the chloroform and hexane extracts were potent inhibitors of K. pneumoniae growth in the liquid dilution assay (LD MIC 95 and 50 $\mu \mathrm{g} / \mathrm{mL}$ respectively) and thus may also be useful in the prevention and treatment of ankylosing spondylitis. Whilst the methanolic, aqueous and ethyl acetate extracts also inhibited the growth of A. baylyi and $S$. pyogenes, the MIC values were $>1000 \mu \mathrm{g} / \mathrm{mL}$ against those bacteria, indicating only low to moderate potency. However, as these bacteria were also resistant against all control antibiotics except gentamycin, the $C$. asiatica extracts may still be useful in the prevention of multiple sclerosis and rheumatic fever.

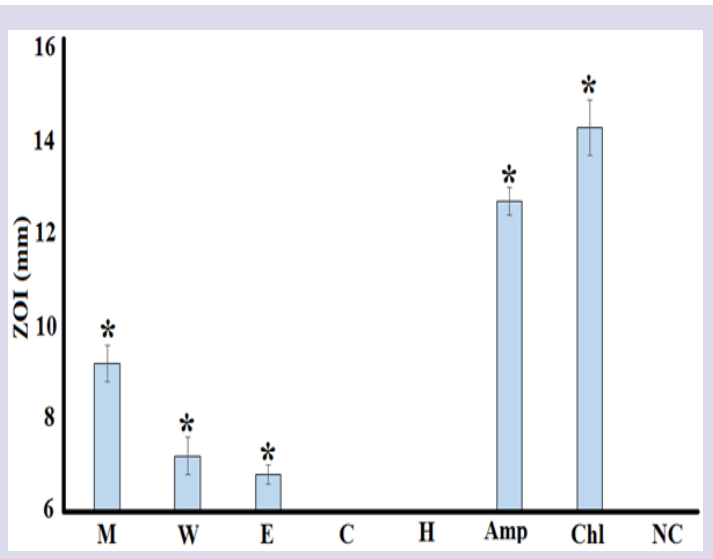

Figure 4: Antibacterial activity of $C$. asiatica extracts against $A$. baylyi (ATCC33304) measured as zones of inhibition $(\mathrm{mm}) . M=$ methanolic extract; $\mathrm{W}=$ aqueous extract; $\mathrm{E}=$ ethyl acetate extract; $\mathrm{C}=$ chloroform extract; $\mathrm{H}=$ hexane extract. The positive controls were Amp (ampicillin $10 \mu \mathrm{g})$ and $\mathrm{Chl}$ (chloramphenicol 10 $\mu \mathrm{g})$. Negative control $(\mathrm{NC})=$ water (1\% DMSO). Results are expressed as mean zones of inhibition of two independent repeats, each with internal triplicates $(n=6) \pm$ SEM. * indicates results that are significantly different to the negative control $(P<0.01)$. 


\section{Fractional inhibitory concentration (FIC) assessment}

Combinational effects on a bacterial trigger of rheumatoid arthritis (Proteus spp.)

Combinations of the $C$. asiatica extracts with conventional antibiotics were tested against $P$. mirabilis and $P$. vulgaris to determine the classes of interactions for these combinations (Table 3). $\Sigma$ FIC values could not be determined for many of the combinations as one or both of the components in the combination were ineffective against the tested bacterium when tested alone. Of the effective combinations, the majority of were non-interactive (approximately $89 \%$ of the inhibitory combinations). Whilst these combinations have no additional benefit over the individual monotherapies alone, the lack of antagonism indicates that taking these therapies in combination would not have detrimental effects. This is important information as allopathic and complementary therapies are often taken concurrently. Three combinations also produced additive effects (methanol extract and chloramphenicol against P. mirabilis; methanol and ethyl acetate extracts in combination with tetracycline against $P$. vulgaris), with $\Sigma$ FIC values of $0.83,0.87$ and 0.98

Table 2: Disc diffusion and liquid dilution MIC values for the C. asiatica extracts against $P$. mirabilis, P. vulgaris, K. pneumoniae, A. baylyi, P. aeruginosa and S. pyogenes growth $(\mu \mathrm{g} / \mathrm{mL})$.

\begin{tabular}{|c|c|c|c|c|c|c|c|c|c|c|c|c|}
\hline \multirow{2}{*}{ EXRACT } & \multicolumn{2}{|c|}{$\begin{array}{c}\text { P. mirabilis } \\
\text { (ATCC33304) }\end{array}$} & \multicolumn{2}{|c|}{$\begin{array}{c}\text { P. vulgaris } \\
\text { (ATCC21719) }\end{array}$} & \multicolumn{2}{|c|}{$\begin{array}{c}\text { K. pneumoniae } \\
\text { (ATCC31488) }\end{array}$} & \multicolumn{2}{|c|}{$\begin{array}{c}\text { A. baylyi } \\
\text { (ATCC21721) }\end{array}$} & \multicolumn{2}{|c|}{$\begin{array}{l}\text { P. aeruginosa } \\
\text { (ATCC39324) }\end{array}$} & \multicolumn{2}{|c|}{ S. pyogenes } \\
\hline & DD MIC & LD MIC & DD MIC & LD MIC & DD MIC & LD MIC & DD MIC & LD MIC & DD MIC & LD MIC & DD MIC & LD MIC \\
\hline W & 1742 & 1570 & $>5000$ & 4822 & $>5000$ & $>5000$ & $>5000$ & $>5000$ & - & - & $>5000$ & 2685 \\
\hline$E$ & 1200 & 850 & 1460 & 1158 & - & - & ND & $>5000$ & - & - & ND & 1688 \\
\hline \multicolumn{13}{|l|}{ Positive controls } \\
\hline Penicillin & ND & 2.5 & ND & 1.25 & ND & - & ND & - & ND & - & ND & - \\
\hline Chloramphenicol & ND & 2.5 & ND & 2.5 & ND & 1.25 & ND & 2.5 & ND & - & ND & - \\
\hline Gentamycin & ND & 1.25 & ND & 1.25 & ND & 0.31 & ND & 0.31 & ND & 0.63 & ND & 0.63 \\
\hline Negative control & ND & - & ND & - & ND & - & ND & - & ND & - & ND & - \\
\hline
\end{tabular}

$\mathrm{M}=$ methanol; $\mathrm{W}=$ water; $\mathrm{E}=$ ethyl acetate; $\mathrm{C}=$ chloroform; $\mathrm{H}=$ hexane. $\mathrm{DD}=$ disc diffusion; $\mathrm{LD}=$ liquid dilution. - indicates no inhibition at any dose tested. Numbers indicate the mean DD MIC and LD MIC values of triplicate determinations, expressed in $\mu \mathrm{g} / \mathrm{mL}$. ND $=$ MIC could not be determined as only a single dose was tested.

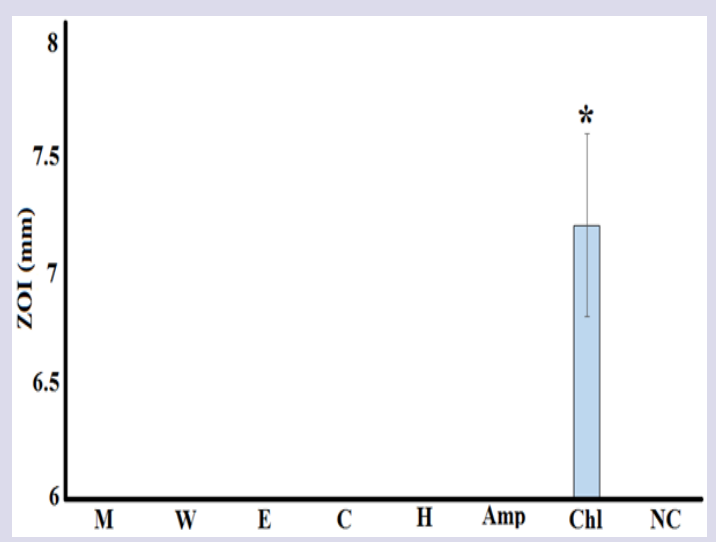

Figure 5: Antibacterial activity of $C$. asiatica extracts against $P$. aeruginosa (ATCC39324) measured as zones of inhibition $(\mathrm{mm}) . \mathrm{M}=$ methanolic extract; $W=$ aqueous extract; $E=$ ethyl acetate extract; $C=$ chloroform extract; $\mathrm{H}=$ hexane extract. The positive controls were Amp (ampicillin $10 \mu \mathrm{g})$ and $\mathrm{Chl}$ (chloramphenicol 10 $\mu \mathrm{g})$. Negative control $(\mathrm{NC})=$ water (1\% DMSO). Results are expressed as mean zones of inhibition of two independent repeats, each with internal triplicates $(n=6) \pm$ SEM. * indicates results that are significantly different to the negative control $(P<0.01)$.

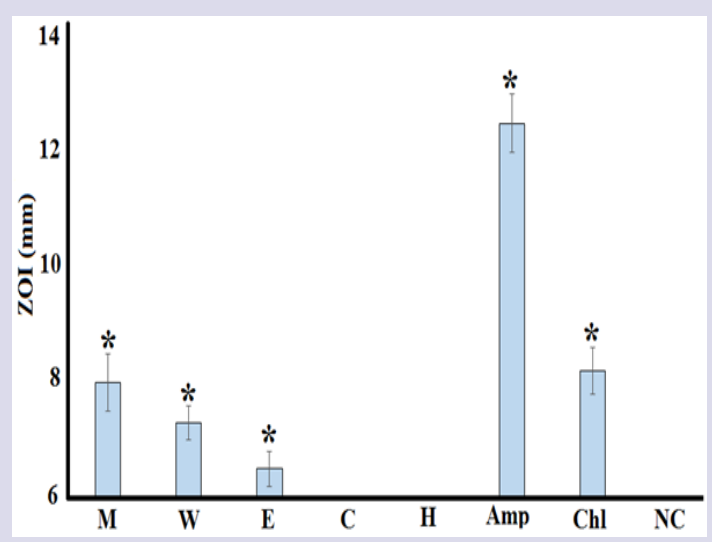

Figure 6: Antibacterial activity of $C$. asiatica extracts against a clinical isolate of $S$. pyogenes measured as zones of inhibition $(\mathrm{mm}) . \mathrm{M}=$ methanolic extract; $\mathrm{W}=$ aqueous extract; $\mathrm{E}=$ ethyl acetate extract; $\mathrm{C}=$ chloroform extract; $\mathrm{H}=$ hexane extract. The positive controls were Amp (ampicillin $10 \mu \mathrm{g}$ ) and $\mathrm{Chl}$ (chloramphenicol $10 \mu \mathrm{g}$ ). Negative control (NC) = water (1\% DMSO). Results are expressed as mean zones of inhibition of two independent repeats, each with internal triplicates $(n=6) \pm$ SEM. * indicates results that are significantly different to the negative control $(P<0.01)$. 
respectively. As these combinations have enhanced effects compared to either component alone, they would be beneficial for the treatment and prevention of rheumatoid arthritis (and other diseases causes by Proteus spp.). None of the combinations produced synergistic effects.

\section{Combinational effects on a bacterial trigger of ankylosing spondylitis (K. pneumoniae)}

Two synergistic interactions were noted for combinations of the $C$. asiatica extracts and conventional antibiotics against the growth of $K$. pneumoniae (Table 3). Interestingly, both of these combinations contained the methanolic extract with either chloramphenicol or tetracycline ( $\Sigma$ FIC 0.43 and 0.37 respectively). These combinations may therefore be effective in the prevention and treatment of ankylosing spondylitis (and other diseases caused by K. pneumoniae). Of further note, combinations of chloramphenicol with chloroform or hexane extracts and the hexane extract with erythromycin or tetracycline, produced additive effects. This indicates that these combinations may also be beneficial in the treatment of those diseases due to their increased growth inhibitory efficacies compared to the individual components. All other combinations were either non-interactive or ineffective.

\section{Combinational effects on bacterial triggers of multiple sclerosis (A. baylyi and P. aeruginosa)}

A range of interactions were observed for combinations of the $C$. asiatica extracts and conventional antibiotics against A. baylyi (Table 3). Combinations of the methanolic extract with erythromycin or tetracycline resulted in additive interactions. Similarly, the ethyl acetate-tetracycline combination also produced additive effects. Thus, these combinations may be beneficial due to their increased growth inhibitory efficacies. As A. baylyi is one of the bacterial triggers of multiple sclerosis, ${ }^{4}$ these combinations may be beneficial in the prevention and treatment of that disease. The majority of the other combinations were non-interactive.

Table 3: $\Sigma$ FIC values of $C$. asiatica extracts in combination with conventional antibiotics against P. mirabilis, P. vulgaris, K. pneumoniae, A. baylyi and S. pyogenes.

\begin{tabular}{|c|c|c|c|c|c|c|}
\hline & & Penicillin & Chloramphenicol & Gentamycin & Erythromycin & Tetracycline \\
\hline \multirow{5}{*}{ 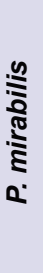 } & M & 1.75 & 0.83 & 2.2 & 1.05 & - \\
\hline & $\mathbf{W}$ & 1.3 & 1.3 & 1.8 & 1.8 & - \\
\hline & $E$ & 2.2 & 1.1 & 2.3 & 1.27 & - \\
\hline & C & - & - & - & - & - \\
\hline & H & - & - & - & - & - \\
\hline \multirow{5}{*}{$\begin{array}{l}\frac{n}{2} \\
\frac{\pi}{3} \\
\frac{5}{3} \\
0\end{array}$} & M & 1.63 & 1.45 & 2.2 & 1.2 & 0.87 \\
\hline & $\mathbf{W}$ & 1.27 & 1.6 & 2.4 & 1.83 & 1.17 \\
\hline & $E$ & 1.45 & 1.53 & 1.9 & 1.47 & 0.98 \\
\hline & C & - & - & - & - & - \\
\hline & $\mathbf{H}$ & - & - & - & - & - \\
\hline \multirow{5}{*}{ 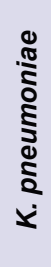 } & M & - & 0.43 & 2.9 & - & 0.37 \\
\hline & W & - & 1.46 & 2.7 & 1.45 & 2.3 \\
\hline & $E$ & - & - & - & - & - \\
\hline & C & - & 0.92 & 2.9 & - & - \\
\hline & H & - & 0.58 & 3.2 & 0.66 & 0.85 \\
\hline \multirow{5}{*}{$\begin{array}{l}\underset{\nwarrow}{\nwarrow} \\
\stackrel{\nwarrow}{\Omega} \\
\dot{\leftarrow}\end{array}$} & M & - & 1.5 & $\underline{4.2}$ & 0.7 & 0.65 \\
\hline & W & - & 2 & 3.5 & 1.5 & 1.25 \\
\hline & $\mathbf{E}$ & - & 1.75 & 2.6 & 1.2 & 0.8 \\
\hline & C & - & - & - & - & - \\
\hline & $\mathbf{H}$ & - & - & - & - & - \\
\hline \multirow{5}{*}{ 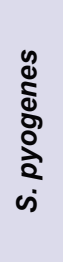 } & $\mathbf{M}$ & - & - & $\underline{4.2}$ & - & 1.5 \\
\hline & $\mathbf{W}$ & - & - & 3.0 & - & 1.5 \\
\hline & $E$ & - & - & - & - & - \\
\hline & C & - & - & - & - & - \\
\hline & $\mathbf{H}$ & - & - & - & - & - \\
\hline
\end{tabular}

$\mathrm{M}=$ methanol; $\mathrm{W}=$ water; $\mathrm{E}=$ ethyl acetate; $\mathrm{C}=$ chloroform; $\mathrm{H}=$ hexane - indicates that the $\Sigma \mathrm{FIC}$ could not be determined. $\mathrm{M}=$ methanol; $\mathrm{W}=$ water; $\mathrm{E}$ = ethyl acetate; $\mathrm{C}=$ chloroform; $\mathrm{H}=$ hexane; - indicates that the $\Sigma \mathrm{FIC}$ could not be determined; Synergy (bold highlighting) $=\leq 0.5$; Additive (italics highlighting) $=>0.5-1.0$; Indifferent (no highlighting) $=>1.0-\leq 4$; Antagonistic (underlined highlighting) $=>4.0$. Numbers indicate the mean $\Sigma$ FIC values of 4 determinations. 
Table 4: $\mathrm{LC}_{50}$ values determined for C. asiatica extracts in the Artemia nauplii and HDF bioassays following $24 \mathrm{hr}$ exposure.

\begin{tabular}{ccc}
\hline \multirow{2}{*}{ Extract } & \multicolumn{2}{c}{$\mathrm{LC}_{50}$ value $(\mu \mathrm{g} / \mathrm{mL})$} \\
\cline { 2 - 3 } M & ALA & HDF assay \\
\hline W & 1765 & - \\
E & 2468 & - \\
C & - & - \\
H & - & \\
PC & - & NT \\
\hline
\end{tabular}

- indicates that less than $50 \%$ mortality was induced by the extract at all concentrations tested. ALA = Artemia nauplii toxicity assay; $\mathrm{HDF}=$ human dermal fibroblast toxicity assay; $\mathrm{M}=$ methanolic extract; $\mathrm{W}=$ aqueous extract; $\mathrm{E}=$ ethyl acetate extract; $\mathrm{C}=$ chloroform extract; $\mathrm{H}=$ hexane extract; $\mathrm{NT}=$ Not tested.

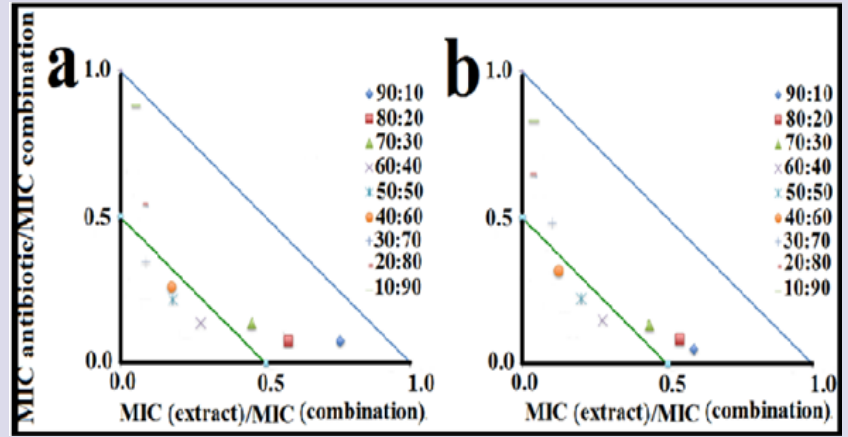

Figure 7: Isobologram for combinations of the methanolic C. asiatica extract with (a) chloramphenicol or (b) tetracycline against $K$. pneumoniae. Results represent mean FIC values of four replicates. Ratio = \% extract:\% antibiotic. Ratios lying on or underneath the $0.5: 0.5$ line are considered to be synergistic $(\Sigma \mathrm{FIC} \leq 0.5)$. Any points between the 0.5:0.5 and 1.0:1.0 lines are deemed additive $(\Sigma \mathrm{FIC}>0.5-1.0) . \mathrm{Chl}=$ chloramphenicol.
Whilst there is no added benefit in combining these therapies, their concurrent use would not decrease the activity of either component and therefore they may be safely used in combination without decreasing the efficacy of the treatment. However, one antagonistic interaction was detected (methanolic extract with gentamycin). This combination should therefore be avoided for the prevention and treatment of multiple sclerosis (and other diseases caused by A. baylyi). No interactive effects could be determined against $P$. aeruginosa as all $C$. asiatica extracts and most of the conventional antibiotics were completely ineffective against this bacterium. It was therefore not possible to calculate $\Sigma F I C$ values for combinations containing those components.

\section{Combinational effects on a bacterial trigger of rheumatic fever (S. pyogenes)}

The combinational antimicrobial effects of the $C$. asiatica extracts with various conventional antibiotics against $S$. pyogenes are summarised in Table 3. The majority of the combinations produced non-interactive effects. These combinations therefore have no therapeutic advantage over the use of either monotherapy alone, although the use of the combination would also not decrease the effects of either component. No synergistic or additive effects were detected for any combination. It is noteworthy that this bacterial strain displayed substantial resistance to most of the conventional antibiotics. Indeed, only gentamycin and tetracycline inhibited the growth of this bacterium, although the relatively high MIC for tetracycline $(2.5 \mu \mathrm{g} / \mathrm{mL})$ indicates only low efficacy. Perhaps of greater interest, the combination of the methanolic extract and gentamycin was antagonistic. This combination should therefore be avoided as a chemotherapeutic option to treat $S$. pyogenes infections.

Varied ratio combination studies (isobolograms)

The combination of the methanolic $C$. asiatica extract with chloramphenicol (Figure 7a) or tetracycline (Figure 7b) induced synergistic interactions against $K$. pneumoniae and therefore these combinations were further investigated by isobologram analysis across a range of ratios to determine the ideal combination compositions to obtain synergy. All combination ratios containing $30-60 \%$ of the methanolic extract produced synergistic interactions in combination with chloramphenicol against K. pneumoniae (Figure 7a). Thus these combination ratios would be beneficial to enhance $K$. pneumoniea growth inhibition. However, bacteria would be less likely to develop resistance when combinations are used in ratios which minimise the amount of conventional antibiotic used. Thus, for long term prophylactic treatment (as would be required to prevent and treat ankylosing spondylitis), the ideal extract:chloramphenicol ratio may be 60:40. However, when used for the treatment of acute infections (e.g. lung infections), the ratio which maximises the efficacy of the treatment (i.e. the 30:70 ratio) may be the preferred option.

Isobologram analysis for the combination of methanolic C. asiatica extract and tetracycline showed synergistic interactions against $K$. pneumoniae across a wide range of ratios (Figure $7 \mathrm{~b}$ ). All combinations containing between 40-60\% methanolic C. asiatica extract produced synergistic effects. All other combination ratios were additive. Therefore, the combination containing $40 \%$ methanolic $R$. canina extract and $60 \%$ tetracycline was deemed to be the best combination ratio for prophylactic treatment to prevent ankylosing spondylitis, as well as decreasing the possibility of further increasing bacterial resistance to chloramphenicol.

\section{Quantification of toxicity}

No $\mathrm{LC}_{50}$ values were determined for the ethyl acetate, chloroform or hexane extracts as $<50 \%$ mortality was seen in all tested concentrations (Table 4). In contrast, LC $_{50}$ values of 1765 and $2468 \mu \mathrm{g} / \mathrm{ml}$ were determined for the methanolic and aqueous extracts respectively. As extracts with $\mathrm{LC}_{50}$ values $<1000 \mu \mathrm{g} / \mathrm{ml}$ towards Artemia nauplii have previously been defined as being toxic in this assay [16], all extracts were deemed to be nontoxic. Furthermore, all plant extracts demonstrated a lack of toxicity towards normal human primary dermal fibroblasts, with cellular viability for all tests substantially $>50 \%$ of the untreated control. All extracts were therefore deemed to be nontoxic.

\section{DISCUSSION}

This study investigated the ability of $C$. asiatica extracts to inhibit the growth of some bacterial triggers of autoimmune inflammatory diseases, both alone and in combination with conventional antibiotics. Several $C$. asiatica extracts were identified as effective bacterial growth inhibitors. The methanolic extract was particularly strong inhibitors of $P$. mirabilis, $P$. vulgaris and K. pneumoniae growth, with MIC values as low as $672 \mu \mathrm{g} / \mathrm{mL}$. Whilst these extracts also inhibited the growth of A. baylyi, P. aeruginosa and $S$. pyogenes, the MIC values were generally substantially $>1000 \mu \mathrm{g} /$ $\mathrm{mL}$ and are thus indicative of only low to moderate inhibitory activity. Interestingly, the chloroform and hexane extracts were particularly good

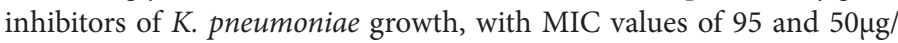
$\mathrm{mL}$ respectively, indicating the inhibitory compounds may be nonpolar in nature. Whilst a detailed investigation of the phytochemistry of the 
C. asiatica extracts was beyond the scope of this study, the qualitative phytochemical studies highlighted several phytochemical classes that may contribute to the bacterial growth inhibitory activity. Interestingly, the methanolic and aqueous C. asiatica extracts had relatively high abundances of polyphenolics and flavonoids, as well as lower levels of tannins, triterpenoids and saponins. Many studies have reported potent antibacterial activities for a wide variety of flavonoids. ${ }^{19-21}$ This has been attributed to a variety of mechanisms, including their ability to complex with extracellular and soluble proteins, as well as bacterial cell walls.22 Similarly, multiple tannins have broad spectrum antibacterial activity via a variety of intra- and extra-cellular mechanisms, including the precipitation of microbial proteins. ${ }^{23}$ It is likely that other phytochemical classes may also contribute to the growth inhibitory properties of these extracts. Therefore, phytochemical evaluation studies and bioactivity driven isolation of the active components are required to evaluate the mechanism of the C. asiatica extracts growth inhibitory activity.

The studies combining the extracts with conventional antibiotics also highlighted other therapeutic options. In particular, combinations containing methanolic $C$. asiatica extract and either chloramphenicol or tetracycline produced synergistic effects against K. pneumoniae, despite this bacterium being relatively resistant against both of these antibiotics. It appears that the extract functioned as a resistance-modifying agent, inhibiting bacterial resistance mechanisms and allowing the antibiotic to function with improved efficacy. This is particularly interesting and highlights an effective treatment modality for use against resistant K. pneumoniae infections. As several multi-antibiotic strains of this bacterium (and one strain that was resistant to all commonly used clinical antibiotics) have recently been reported, ${ }^{4}$ this is a particularly interesting and relevant finding. Furthermore, several additive combinations were also detected. Whilst the extract does not increase the activity of the antibiotics to as great an extent in these combinations, the potency of the treatment is still substantially increased compared to either monotherapy when used separately. Thus, these combinations would also be beneficial when used as a preventative therapy for ankylosing spondylitis, or for other diseases caused by K. pneumoniae.

Several combinations also produced additive effects against other bacterial triggers of autoimmune diseases. The methanolic extract (in combination with chloramphenicol) against $P$. mirabilis, the methanolic and ethyl acetate extracts (in combination with tetracycline) against $P$. vulgaris and the methanolic and ethyl acetate extracts (in combination with erythromycin or chloramphenicol) against A. baylyi all produced enhanced efficacy. Therefore, the use of these combinations would be beneficial in the treatment of rheumatoid arthritis and multiple sclerosis, as well, as other diseases caused by these bacteria.

A further trend was evident in our study: most of the extract-antibiotic combinations which did not produce synergistic or additive effects, generally did not greatly affect the efficacy of the antibiotic i.e. They appear to not counter-indicate with the antibiotics tested in this study. This is important as many users of herbal and traditional medicines self-diagnose/treat, often with multiple therapies concurrently. Thus, an understanding of drug herbal medicine interactions is important. Only two combinations tested in this study produced antagonistic interactions with the conventional antibiotics (methanolic extract in conjunction with gentamycin against $A$. baylyi or S. pyogenes). This is an important finding and highlights that this combination should be avoided when treating A. baylyi and S. pyogenes infections. Interestingly, previous studies indicate that antagonistic combinations of plant extracts with gentamycin are not uncommon. ${ }^{24}$

Microbes have developed numerous resistance mechanisms to avoid the effects of antibiotics. One main method is through the use of multi-drug resistant (MDR) efflux pumps which are encoded chromosomally and are used to rapidly remove antibiotics that have entered the bacterial cells, thus rendering them resistant to the effects of the antibiotic. ${ }^{25,26}$ A single pump may allow the bacteria to escape several types of antimicrobials. When these efflux pumps are inhibited, the intracellular concentration of antibiotic will increase, allowing the treatment to once again be effective. Interestingly, many plants possess multi-drug resistance (MDR) pump inhibitors in order to enhance the activity of their own natural antimicrobial compounds. Such MDR pump inhibitors become effective tools when used in combination with some previously ineffective/resistance prone antibiotic compounds and several examples have previously been reported..$^{27}$ Isoflavones isolated from Lupinus argenteus Pursh potentiate the activity of the natural plant antibiotic berberine as well as the synthetic fluoroquinoline antibiotic, norfloxacin as inhibitors of $S$. aureus growth. ${ }^{27}$ That study reported that the isoflavone allows a greater concentration of berberine to occur inside the bacteria by inhibiting the efflux mechanism (MDR pump). Similarly, Mezoneuron benthamianum Baill. and Securinega virosa (Roxb. Ex Willd) Baill. extracts act as efflux pump inhibitors for fluoroquinolone, tetracycline and erythromycin in resistant strains of $S$. aureus (MRSA). ${ }^{28}$ As a consequence, the M. benthamianum ethanol extract and chloroform extract of $S$. virosa reduce the MIC (minimum inhibitory concentration) of norfloxacin against $S$. aureus by a factor of 4 .

In our study, all bacterial species were resistant to penicillin-G, chloramphenicol, erythromycin and tetracycline, with only low susceptibility or complete resistance to each antibiotic. All of these antibiotics are susceptible to resistance due to efflux pumps. ${ }^{27,29} \mathrm{~A}$ single pump can provide bacteria with resistance to a wide array of chemically and structurally diverse antibiotics and it is not uncommon for an organism to code for more than one efflux pump. ${ }^{27,29}$ It is therefore imperative to identify agents that can block the efflux mechanism (efflux pump inhibitors - EPIs) or alter the process of efflux and in so doing, extend the life of existing antibacterial drugs. Plants produce various secondary metabolites that are used as defense mechanisms against pathogenic invaders. Some plants produce antimicrobials which, along with other compounds, inhibit the efflux of those antimicrobials from a bacterial cell. There are currently no EPI/antimicrobial drug combinations on the market, although research into identifying potential EPIs is ongoing. ${ }^{27}$ The synergistic interactions in our study suggests the possibility of a common EPI in the $C$. asiatica extracts that could be inhibiting a MDR efflux pump in these bacteria.

Alternatively (or in addition to MDR efflux pumps), the bacteria screened in our study may have acquired genes encoding for reduced-affinity penicillin-binding protein $2 \mathrm{a}$ (PBP2a) (rendering $\beta$-lactam antibiotics ineffective).$^{28}$ As penicillin binding proteins are a group of protein enzymes, these phytochemicals may form nonspecific interactions and affect the bacterial cell wall biosynthesis. The $C$. asiatica extracts may also contain a $\beta$-lactamase inhibitor. $\beta$-lactamases are the major defense of gram-negative bacteria against $\beta$-lactam antibiotics. ${ }^{30}$ Clavulanic acid is an irreversible $\beta$-lactamase inhibitor, which in combination with $\beta$-lactam antibiotics can block the bacterial antimicrobial resistance mechanism. ${ }^{31}$ Further studies are required to identify whether extract compounds mirror the chemical and biological characteristics of clavulanic acid (i.e. the presence of a $\beta$-lactam ring).

Ultimately, the preparation of combinations of $C$. asiatica extracts (or purified compounds) with conventional antibiotic will depend on the nature of the pathogen and of the disease treated. In general, combinations of antibiotic with pure C. asiatica derived compounds would be preferred for acute infections as they are much less complex, easier to standardize and have lower chances of unwanted side effects. The use of crude extracts in these preparations is also effective and may still be acceptable to treat some diseases. However, when treating chronic 
illness, or using a combinational approach to prevent illness (as would be required in preventing autoimmune inflammatory diseases), the use of a pure potentiator compound in combination with the antibiotic may not be preferred. Continuous exposure of bacteria to a pure antibiotic (or to a combination of a single antibiotic and single potentiator) is likely to induce resistance to one or both of the compounds in the bacteria. Indeed, some E. coli strains are now resistant to amoxicillinclavulanic acid combinations. ${ }^{32}$ However, crude plant extracts often contain numerous antibacterial compounds which may affect multiple bacterial targets. Thus, using a plant extract (rather than pure plant compounds) in combination with an antibiotic is less likely to result in resistant bacteria. Indeed, we were unable to find reports of any bacteria developing resistance to a crude plant extract. For this reason, when recommending preferred combination ratios throughout this study, we have recommended two different ratios for acute and chronic conditions. The lowest extract:highest antibiotic ratio which produced synergy has been deemed as the ideal ratio for treating acute bacterial infections, whilst we deemed the highest extract:lowest antibiotic ratio which produced synergy to be preferred for preventing and treating chronic disease

\section{CONCLUSION}

The results of this study demonstrate the potential of the C. asiatica extracts in inhibiting the growth of some bacterial triggers of autoimmune inflammatory diseases. Extract components may also potentiate the activity of antibiotics that are relatively ineffective alone. Therefore, a combinational approach not only increases the effectiveness of these antibiotics, but also may also potentially reduce the side effects and reduce the development of drug resistant pathogens. Isolation of the bioactive and potentiating compounds may be beneficial in drug design against several bacteria including the microbial triggers of rheumatoid arthritis, ankylosing spondylitis and multiple sclerosis.

\section{ACKNOWLEDGEMENT}

Financial support for this work was provided by the Environmental Futures Research Institute and the School of Natural Sciences, Griffith University, Australia.

\section{CONFLICT OF INTEREST}

The authors declare that they have no competing interests.

\section{ABBREVIATIONS}

ALA: Artemia lethality assay; DMSO: Dimethyl sulfoxide; EPI: Efflux pump inhibitor; FIC: Fractional inhibitory concentration; HDF: Human dermal fibroblasts; $\mathbf{L C}_{50}$ : The concentration required to achieve $50 \%$ mortality; MIC: Minimum inhibitory concentration; MDR: Multi-drug resistant; ZOI: Zone of inhibition.

\section{REFERENCES}

1. Davies J. Where have all the antibiotics gone?. Canadian Journal of Infectious Diseases and Medical Microbiology. 2006;17(5):287-90.

2. Cheesman MJ, Ilanko A, Blonk B, et al. Developing new antimicrobial therapies: Are synergistic combinations of plant extracts/compounds with conventiona antibiotics the solution?. Pharmacognosy Reviews. 2017;11(22):57-72. DOI: 10.4103/phrev.phrev_21_17

3. WHO. The Evolving Threat of Antimicrobial Resistance: Options for Action. World Health Organization. 2014. http://apps.who.int/iris/ bitstream/10665/44812/1/9789241503181_eng.pdf. Accessed 14 March 2017.

4. Cock IE, Cheesman M. Chapter 23. The potential of plants of the genus Syzygium (Myrtaceae) for the prevention and treatment of arthritic and autoimmune diseases. In Bioactive Food as Dietary Interventions for Arthritis and Related Inflammatory Diseases, $2^{\text {nd }}$ edition; Elsevier Academic Press. 2019;401-24. https://doi.org/10.1016/B978-0-12-813820-5.00023-4
5. Van VS, Viljoen A. Plant-based antimicrobial studies-methods and approaches to study the interaction between natural products. Planta Medica. 2011;77(11):1168-82

6. Cottarel G, Wierzbowski J. Combination drugs, an emerging option for antibacterial therapy. Trends in Biotechnology. 2007;25(12):547-55.

7. Hemaiswarya S, Kruthiventi AK, Doble M. Synergism between natural products and antibiotics against infectious diseases. Phytomedicine. 2008;15(8):639-52

8. Kartnig T. Clinical applications of Centella asiatica (L.) Urb. Herbs, Spices and Medicinal Plants: Recent Advances in Botany, Horticulture and Pharmacology. Psychology Press. 1988;3:145-73.

9. Awang DV. Gotu kola. CPJ. Canadian Pharmaceutical Journal. 1998;131(7):42.

10. Oyedeji OA, Afolayan AJ. Chemical composition and antibacterial activity of the essential oil of Centella asiatica. Growing in South Africa. Pharmaceutical Biology. 2005;43(3):249-52

11. Dash BK, Faruquee HM, Biswas SK, et al. Antibacterial and antifungal activities of several extracts of Centella asiatica L. against some human pathogenic microbes. Life Sciences and Medicine Research. 2011;2011:1-5.

12. Courtney J, Sirdaarta J, Matthews B, et al. Tannin components and inhibitory activity of Kakadu plum leaf extracts against microbial triggers of autoimmune inflammatory diseases. Pharmacognosy Journal. 2015;7(1):18-31. 2015. DOI: 10.5530/pj.2015.7.2

13. Vesoul J Cock IE. The potential of bunya nut as an antibacterial food agent Pharmacognosy Communications. 2012;2(1):72-9. DOI: 10.5530/pc.2012.1.13

14. Eloff JN. A Sensitive and quick microplate method to determine the minimal inhibitory concentration of plant extracts for bacteria. Planta Medica. 1998;64(08):711-3

15. Hübsch Z, Van ZRL, Cock IE, et al. Interactive antimicrobial and toxicity profiles of conventional antimicrobials with Southern African medicinal plants. South African Journal of Botany. 2014;93:185-97. DOI: 10.1016/j.sajb.2014.04.005

16. Ruebhart D, Wickramasinghe W, Cock IE. Protective efficacy of the antioxidants vitamin E and Trolox against Microcystis aeruginosa and microcystin-LR in Artemia franciscana nauplii. Journal of Toxicology and Environmental Health, Part A. 2009;72(24):1567-75. DOI: 10.1080/15287390903232459

17. Sirdaarta J, Cock IE. Vitamin E and Trolox ${ }^{\mathrm{TM}}$ reduce toxicity of Aloe barbadensis Miller juice in Artemia franciscana nauplii but individually are toxic at high concentrations. Internet J Toxicol. 2008;5(1)

18. Shalom J Cock IE. Terminalia ferdinandiana Exell. fruit and leaf extracts inhibit proliferation and induce apoptosis in selected human cancer cell lines. Nutrition and Cancer. 2018;70(4):1-15. DOI: 10.1080/01635581.2018.1460680

19. Cock IE. The phytochemistry and chemotherapeutic potential of Tasmannia lanceolata (Tasmanian pepper): A review. Pharmacognosy Communications. 2013;3(4):13-25

20. Cock IE. The genus Aloe: Phytochemistry and therapeutic uses including treatments for gastrointestinal conditions and chronic inflammation. Progress in Drug Research. 2015;70:179-236

21. Cock IE. The medicinal properties and phytochemistry of plants of the genus Terminalia (Combretaceae). Inflammopharmacology. 2015;23(5):203-29.

22. Kaur GJ, Arora DS. Antibacterial and phytochemical screening of Anethum graveolens, Foeniculum vulgare and Trachyspermum ammi. BMC Complementary and Alternative Medicine. 2009;9(1):30.

23. Buzzini $P$, Arapitsas $P$, Goretti M, et al. Antimicrobial activity of hydrolysable tannins. Medicinal Chemistry. 2008;8(12):1179-87.

24. Toroglu S. In-vitro antimicrobial activity and synergistic/antagonistic effect of interactions between antibiotics and some spice essential oils. Journal of Environmental Biology. 2011;32(1):23-9.

25. Cowan MM. Plant products as antimicrobial agents. Clinical Microbiology Reviews. 1999:12(4):564-82

26. Chung PY, Navaratnam P, Chung LY. Synergistic antimicrobial activity between pentacyclic triterpenoids and antibiotics against Staphylococcus aureus strains. Annals of Clinical Microbiology and Antimicrobials. 2011;10(1):25.

27. Morel C, Stermitz FR, Tegos G, Lewis K. Isoflavones as potentiators of antibacterial activity. Journal of Agriculture and Food Chemistry. 2003;51(9):5677-9.

28. Dickson RA, Houghton PJ, Hylands PJ, Gibbons S. Antimicrobial, resistancemodifying effects, antioxidant and free radical scavenging activities of Mezoneuron benthamianum Baill., Securinega virosa Roxb. and WIld. and Microglossa pyrifolia Lam. Phytotherapy Research. 2006;20(1):41-5.

29. Sahli AA, Abdulkhair WM. Inhibition of beta-lacamase enzyme of Pseudomonas aeruginosa by clavulanic acid of Rumex vesicarius L. African Journal of Agricultutal Research. 2011;6(12):2908-15

30. Stavrim M, Piddock LJV, Gibbons S. Bacterial efflux pump inhibitors from natural sources. Journal of Antimicrobial Chemotherapy. 2007;59(6):1247-60.

31. Ramón-Garcia S, DelGonzález RR, Villarejo AS, Sweet GD, Cunningham F, Barros D, et al. Repurposing clinically approved cephalosporin's for tuberculosis therapy. Scientific Reports. 2016;6(1):1-4.

32. Oteo J, Campos J, Lázaro E, Cuevas O, Garcia-Cobos S, Pérez-Vázquez M et al. Increased amoxicillin-clavulanic acid resistance in Escherichia coli blood isolates, Spain. Emerging Infectious Diseases. 2008;14(8):1259-62. 


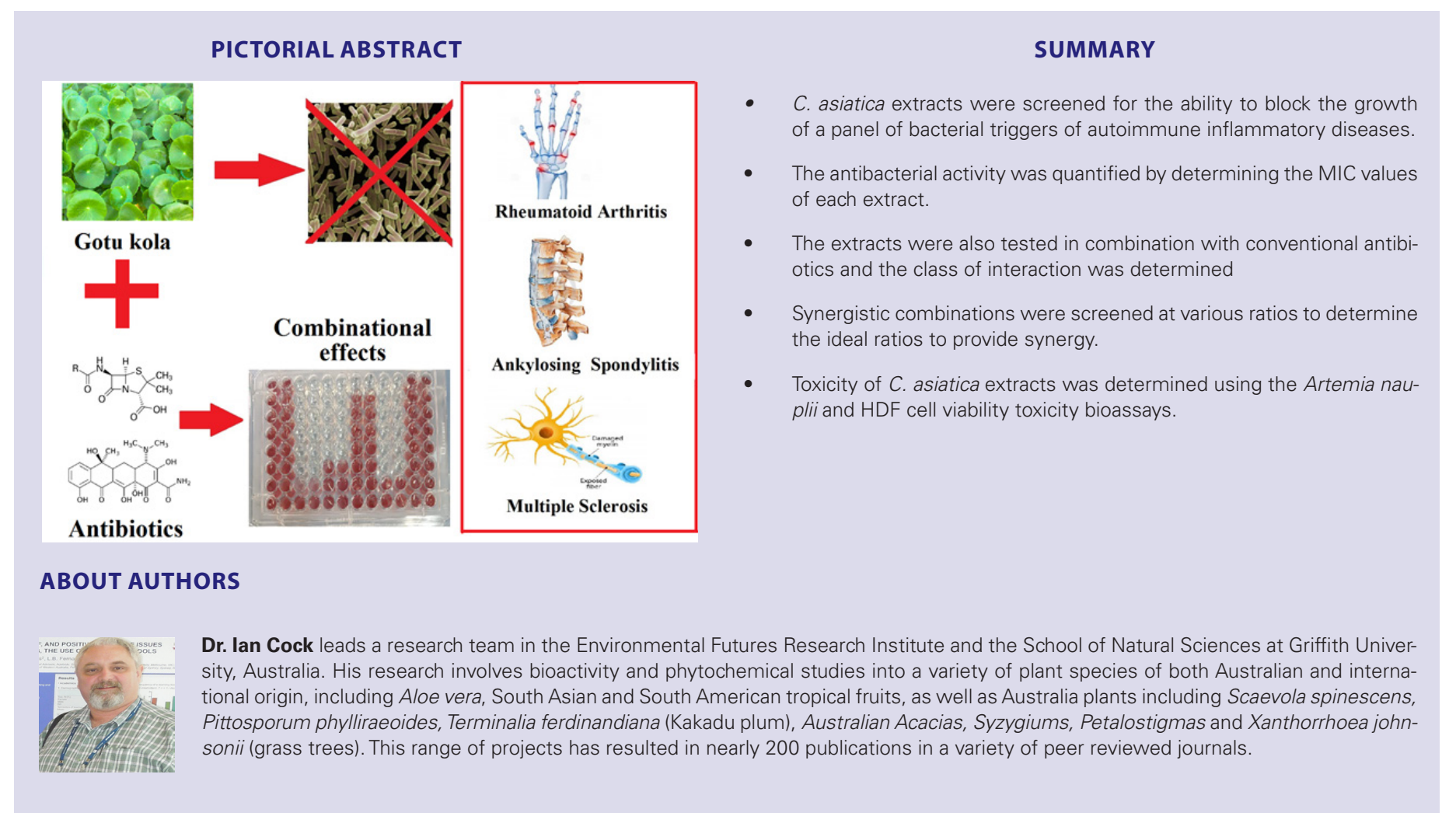

